\title{
Increasing Family Safety and Decreasing Parental Stress and Child's Social-Emotional Problems with Resolutions Approach: a Single-Case Experimental Design Study Protocol
}

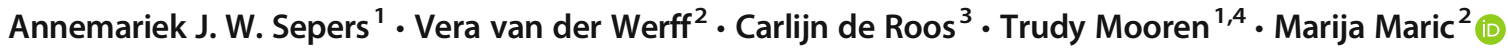

Published online: 27 April 2019

(C) The Author(s) 2019

\begin{abstract}
The present study describes a Single-Case Experimental Design (SCED) research protocol. The outlined research is aimed at investigating the effectiveness and potential mechanisms of the Resolutions Approach (RA), a multidisciplinary intervention to stop child abuse and enhance safety in the families. Given the heterogeneity of the population and innovativeness of the topic, a SCED with a baseline period (A-phase) followed by a treatment period (B-phase) is designed. Participants will be fifteen families with children between 8 and 18 years in which specific signs of current child abuse are determined by more than one informant. The RA is a 20-session protocol implemented in an individual, family and social network context. Assessments of primary (incidents of child abuse) and secondary (child's emotional and behavioral problems, parental stress, closeness of child-parent relationship) outcomes will take place at the start of the baseline period, at pre- and post-treatment, and at two follow-ups. Personalised, idiosyncratic, assessments of the main family problems will be administered on a weekly base. At post-treatment, a qualitative interview is administered in the families examining the most potent mechanisms of change and treatment components. During social network meetings, safety and openness of communication about child abuse is assessed. This study responds to a need for evidencebased interventions for mental health workers dealing with child abuse. Limitations such as bias in the parental reports of child abuse are discussed. Trial registration: Dutch Trial Register: NTR6757. Registered (retrospectively) 04 November 2017.
\end{abstract}

Keywords Child abuse $\cdot$ Multidisciplinary treatment $\cdot$ Family treatment $\cdot$ Resolutions approach $\cdot$ Effectiveness $\cdot$ Mechanisms of change $\cdot$ Single-case experimental design

Marija Maric

m.maric@uva.nl

Annemariek J. W. Sepers

a.sepers@centrum45.nl

Vera van der Werff

v.vanderwerff@uva.nl

Carlijn de Roos

c.deroos@debascule.com

Trudy Mooren

t.mooren@centrum45.nl

1 Arq Psychotrauma Expert Group, Nienoord 13, 1112 XE Diemen, the Netherlands

2 Department of Developmental Psychology, University of Amsterdam, Nieuwe Achtergracht 129B, 1018 WT Amsterdam, The Netherlands

3 De Bascule, Academic Centre for Child and Adolescent Psychiatry, Amsterdam, The Netherlands

4 Department of Clinical Psychology, Utrecht University, Heidelberglaan 1, $3584 \mathrm{CH}$ Utrecht, The Netherlands

\section{Background}

Child abuse refers to sexual, physical and emotional abuse and neglect, being a witness to chronic or severe domestic violence, and educational neglect (Sedlak et al. 2010). Worldwide, millions of children are being maltreated. The overall estimated prevalence rates of child abuse and neglect vary between three and 363 per 1000 depending on the type of abuse (physical vs. emotional) and informant (self vs. otherreported) (Stoltenborgh et al. 2015). For example, according to the Fourth National Incidence Study of Child Abuse and Neglect (Sedlak et al. 2010) 39,5 per 1000 children in the United States were maltreated in 1 year. In the Netherlands, the year prevalence is 33,8 per 1000 children, according to the Second National Prevalence Study on Maltreatment of Children and Youth (Euser et al. 2013)

The mental and physical consequences of child abuse are debilitating for the child's physical, social-emotional and cognitive development. Literature reviews show that children 
who are experiencing abuse may manifest both internalising and externalising behavior problems (Mabanglo 2002; Maguire et al. 2014). Features of ADHD, PTSD, emotion regulation problems, poor social skills, low self-esteem, depression, diminished IQ and developmental delays have all been found to be associated with child abuse and neglect (Mabanglo 2002; Maguire et al. 2014). Furthermore, the retrospective longitudinal Adverse Childhood Experiences Study showed that adults who were maltreated including those who have witnessed domestic violence in their youth were more likely to develop physical and mental health problems such as heavy smoking, cancer, severe obesity, and depression in adulthood (Felitti et al. 1998).

Despite the high prevalence rates and severe consequences of child abuse, little is known about effective interventions to diminish incidents of child abuse and to enhance safety in families. In the Netherlands, as well as abroad (e.g., United Kingdom, Australia, Japan), professionals in mental youth care institutions routinely use one of the two solutionfocused interventions in the case of identified child abuse and potentially unsafe home environment: Signs of Safety (SofS) (Turnell and Edwards 1999) or the Resolutions Approach (RA) (Turnell and Essex 2006). Sometimes, a combination of both interventions is used. The SofS intervention was initially developed to create immediate safety for the child directly after child abuse has been signalled, for example by taking the child in foster care. However, this may not be the best solution in the long term. Often, in these families, parents wish to continue living with their child(ren), while child(ren) also want(s) to live with their parents, but without violence. To meet these needs, RA intervention was developed and is used in the clinical practice when the aim is to create and enhance safety for the children in their original family. SofS and RA are designed for all types of child abuse and neglect. In the context of the two methods, alle families are approached in the same way, regardless of the type of abuse. However, the parental behavior of concern is precisely defined from each individuals' perspective, and the safety arrangements are specifically tailored to each family. The safety agreements therefore always meet the risks that the child runs within a specific family.

RA was developed to accommodate the needs of families characterised by the following: (i) there are severe signs of child abuse or neglect; (ii) the parents deny the abuse or neglect, at least partly; (iii) and the family still wants to stay living together. In clinical practice, the Resolution Approach intervention is mostly used with families with alleged child abuse; however, one element from the SofS protocol, (i.e., the safety card; described in the Method section) is added to this protocol. This is also the intervention which is under investigation in this study.

This intervention is conducted in individual, family and social network context and consists of 20 sessions spread over a period of 12 to 18 months. Experiences in clinical practice show that RA techniques stimulate more open communication about child abuse between parents, children and members of the social network and that this, in turn, leads to fewer incidents of child abuse.

Although both RA and SofS have already been widely implemented in clinical practice, and therapists are increasingly trained in these protocols, only a few studies investigated their effectiveness. The implementation of the SofS intervention has been examined in the child protection context in Western Australia (Salveron et al. 2015). Results revealed that the SofS intervention was experienced as a useful method to deal with signs of child abuse by mental health practitioners, and child welfare leaders and supporters, and especially in multidisciplinary, family-work oriented settings. The social workers using SofS reported increased job satisfaction (Government of Western Australia, Department for Child Protection 2011). Further, considerable parental satisfaction regarding cooperation with the social workers using SofS was reported in one other study (Skrypek et al. 2012).

There is only one study available on the effectiveness of RA. Gumbleton (1997) investigated the effectiveness of RA in seventeen families. Findings demonstrated that, in families treated with RA, there was a significantly lower percentage of children that experienced re-abuse. While rates of 25-33\% repeated abuse have been reported after treatment-as-usual, for RA this was only for $3 \%$ of the children (Gumbleton 1997). To our knowledge, there are no other reports of studies concerned with the effectiveness of RA.

Several factors hamper research of the effects of the RA. First, families demonstrate a reluctance to participate in the treatment. Families accused of child abuse and neglect often deny the maltreatment and reject help. Parents may deny child abuse out of shame and fear that child protection services will place the children in foster care. Recent attempts in the Netherlands to investigate the effectiveness of the SofS in the context of a Randomised Controlled Trial (RCT) design, have been unsuccessful because of a lack of families motivated to participate in treatment and/or research (Hammink et al. 2015). A second factor that complicates research in this population is the occurrence of drop-out. The complexity of family problems (e.g., several co-morbidities including alcohol abuse, mental disabilities) may negatively influence a family's commitment to the continuation of the treatment. A third reason that may account for the lack of scientific investigation of the effects of RA is the requirement for the involvement of the family network (family members, neighbours and various professionals) in the treatment process (Turnell and Essex 2006). To ensure the effectiveness of RA, the involvement of all of these parties (and different views about ongoing child abuse) in the research process is essential and therefore presents another additional challenge for research in this specific population. In the project presented in this article, we pay specific 
attention to these obstacles to ensure the successful conduct of this study.

The main goal of this article is to describe the research protocol being utilized in the study investigating the effectiveness of a multidisciplinary treatment RA (including the SofS's treatment safety card component) in families with alleged child abuse.

The primary objective of the research study itself is indeed to investigate the effectiveness of RA. To this end, the effects of RA on new incidents of child abuse, child's emotional and behavioral problems (including posttraumatic stress symptoms), parental stress, and the closeness of the child-parent relationship are examined.

The secondary objective of the research study is to explore the potential mechanisms of change underlying RA effects. Most families keep abuse undisclosed because they feel ashamed or anxious regarding the possibility of out of home placement of their children. Clinical experience suggests that breaking through the secrecy surrounding child abuse and domestic violence, and increasing the openness of communication about child abuse, often reduces parental stress, and is associated with fewer incidents of child abuse during and after the treatment.

\section{Description of the Research Study Methods}

\section{Trial Design}

To investigate the effectiveness of the RA we use a Single-Case Experimental Design (SCED). We use this design for several reasons. In the first place, we learned from previous research on SofS (Hammink et al. 2015; Vink et al. 2017) that investigators did not succeed in including as many participants as necessary to conduct a Randomized Control Trial. Few families were referred and too few parents gave their consent for participation in the research. Furthermore, a SCED is used because of the high complexity and heterogeneity of the sample, the involvement of multiple partners, and innovativeness of the intervention (Maric et al. 2012; Norell-Clarke et al. 2011). The Single-Case Experimental Design (SCED) methodology allows us to investigate treatment effects on a case-by-case basis. SCEDs are an excellent opportunity to stimulate collaboration between clinicians and researchers, unifying research questions that emerge from clinical practice with research methodology to test these questions on a single-client level (Borckardt et al. 2008).

In a SCED study all participants undergo several conditions. In our study an AB-design will be used, as illustrated in Fig. 1. The A-phase is the baseline period between the referral and the start of the treatment (T0-T1) during which we conduct the assessments, and the families do not receive any treatment. Because of the nature of the problem and the need to provide treatment to these families as soon as possible, a naturalistic baseline period is used consisting of a regular waiting period of around 4-5 weeks. The B-phase concerns the period in which the families receive treatment (20 sessions spread over a period of 12 to 18 months) (T1-T2). The participants will receive pre- and post-treatment assessment ( $\mathrm{T} 1$ and $\mathrm{T} 2$, respectively). Additionally, there are two follow-up assessments three and 6 months post-treatment (T3 and T4).

The current study will use both quantitative and qualitative assessment methods. The quantitative measures will be administered at five extensive assessment points (T0-T4) and consist mainly of questionnaires for parents and children, and one pictorial item. During the extensive assessment sessions, children and parents fill out the online questionnaires under the supervision of an independent assessor. In addition, short personalised questionnaires, so-called Idiosyncratic Assessments (IA) (5-10 questions online), will be filled out weekly during the baseline and treatment phases (Weisz et al. 2011). There are several multidisciplinary network meetings during the treatment phase during which parents, children, therapist and social network
Fig. 1 An overview of the design and the assessment procedure. The figure shows the AB-design with the different time points on the $\mathrm{x}$-as. The $\mathrm{y}$-as represents a fictional mean score from one of the outcome measures. The white dots stand for the idiosyncratic assessments, the white square for the interview, the black squares for the extensive assessments, and the black dots for the VAS safety

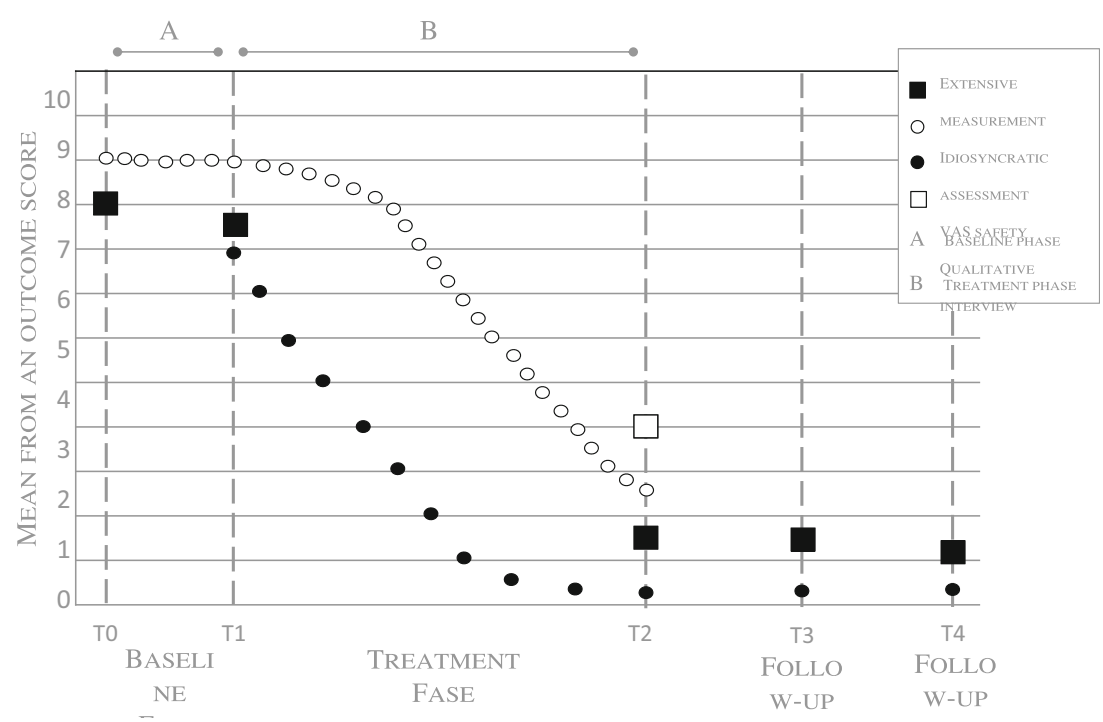


members rate the incidents of child abuse and the openness of communication about child abuse in the family on a Visual Analogue Scale (VAS-scale).

The qualitative measure, a semi-structured interview, will be administered post-treatment (T2). An independent assessor will interview parents and children.

\section{Participants and Recruitment for the Study}

The participants are members of fifteen families with children aged between 8 and 18 years who are referred to four different mental health care centers in the Netherlands specialised in child abuse. The professional initially involved with the family (i.e., child protection worker, neighbourhood team social worker, general practitioner) refers the families to one of the participating mental health care centers. It is possible that some of the families are court obliged to enrol in the program. Usually, the therapist conducting the intake will explore family's interest to participate in this research project. If the family agrees, the therapist hands the case over to the researcher (second author) who provides extensive information about the research project and arranges the informed consent and the research assessments. If the family cannot come to the institution, meetings are organized close to where the family lives.

Inclusion criteria are: (1) there are specific signs of current child abuse, determined by more than one informant. Informants consist of family members, members of the social network of the family, doctors, teachers, police and other professionals; 2) one, or both, of the parents (partially) deny that they have maltreated their children; 3) parents are willing to participate in the intervention and research; 4) working towards safety within the family seems to be an achievable goal for all involved parties; 5) there is an existing safety network of at least one person; 6) the families' case manager (i.e., the child protection worker) is able to attend the multidisciplinary social network meetings.

An exclusion criterium is: Families who do not have a permanent residence or do not speak Dutch.

This study has been approved by the Ethical Board of the Institute of Psychology (University of Amsterdam). Both parents and children ( $>12$ years old) need to provide their active, informed consent before participation in this study. Participation is entirely voluntary, and participants are free to withdraw from the study at any moment without an explanation and without any consequences for their further treatment at the mental health care center.

\section{The Resolutions Approach (RA) Intervention}

Ideally, professional help for abused children is organised in phases. In the first phase, the aim of the intervention is to create a safe environment for the child. If safety is established, in the second phase psychological trauma-related symptoms are considered. If indicated, a trauma-focused treatment can be delivered. In the final phase, plans for monitoring safety in future are organised (Vogtländer and van Arum 2016).

The aim of RA is to create a safe environment for the child through seven steps (Table 1). To this protocol, one additional technique from the SofS intervention (Turnell and Edwards 1999) - the safety card - is added. RA is conducted in an individual, family and social network context and consist of 20 sessions spread over a period of 12 to 18 months. In the research study described in this protocol, each family will go through the entire RA program in the same order (steps 1 to 7). The number of sessions and weeks spent on each step may vary and it depends on factors such as the severity of the suspected abuse and the motivation of the family members. Less motivated parents or parents who are in disagreement will take more time to come to an agreement with each other about each step of the intervention.

A noteworthy feature of RA is the elegant way the method deals with the denial of child abuse and neglect. Denial is seen as a complex interactional process on a continuum (Turnell and Essex 2006). In many cases, parents do not deny all of the accusations nor do they confess to all of them. Parents may deny accusations because confessing may have serious consequences such as losing their jobs, risking prosecution or the breakdown of relationships. In the context of RA, rather than arguing with parents about the past, professionals and families work together towards a safe home environment. This is done through signalling triggers for future abuse situations, preventing unsafe situations for the children, empowering the potentially safer parent and involving the social network of the family. All the professionals involved with the family and the family members work together in social network meetings towards the safety of the children.

\section{Outcome Measures}

Figure 1 and Table 2 display an overview of measures and assessment points in this study.

Primary Outcome Measures: Type and Frequency of Incidents of Child Abuse and Domestic Violence Childhood Trauma Questionnaire-Short Form (CTQ-SF; Bernstein et al. 2003) is a self-report instrument designed to assess emotional and physical neglect, emotional and physical abuse, as well as sexual abuse as reported by the child aged 12-18 (CTQ-SF, 28 items on a 5-point scale). The English CTQ has good validity and is reliable, with a total $\alpha=.97$, and subscale alpha's range from .63 to .95 (Bernstein et al. 1997, 2003). The Dutch CTQ has good internal consistency, convergent validity and reliability (Thombs et al. 2009).

The Conflict Tactics Scale Parent-Child / Child-Parent (CTS-PC/CP; Straus et al. 1998) is a self-report instrument designed to assess the presence and degree of child abuse as 
Table 1 The seven steps of the Resolutions Approach protocol in this study

\begin{tabular}{|c|c|c|}
\hline Step & Number of sessions and participants involved & Activities \\
\hline 1. Preparation & $\begin{array}{l}1 \text { session with the parents } \\
1 \text { phone call with the case manager }\end{array}$ & The therapist explains the approach. \\
\hline \multirow[t]{2}{*}{$\begin{array}{l}\text { 2. Working relationship and } \\
\text { mapping the signals for unsafe } \\
\text { and safe }\end{array}$} & $1-4$ sessions with the parents & $\begin{array}{l}\text { The therapist explores the concerns of parents and other } \\
\text { family-related caretakers. The actual signals of child abuse } \\
\text { and home violence, and the signals of good care of the parent } \\
\text { for the child are mapped using the safety card }{ }^{\mathrm{a}} \text {. }\end{array}$ \\
\hline & 1 session with parents and case manager & $\begin{array}{l}\text { The therapist explores the concerns of childcare, child } \\
\text { protection, the courts, and other family-related caretakers. The } \\
\text { actual signals of child abuse and home violence and the sig- } \\
\text { nals of good care of the parent for the child are mapped using } \\
\text { the safety card }{ }^{\mathrm{a}} \text {. }\end{array}$ \\
\hline 3. Words and pictures & $\begin{array}{l}1-2 \text { sessions with the parents alone } \\
1 \text { session with parents and case manager } \\
1 \text { session with parents, children, case manager } \\
\text { and social network }\end{array}$ & $\begin{array}{l}\text { Parents and therapist construct a narrative in 'words and pictures' } \\
\text { based on four questions: "Who's worried? What are you worried } \\
\text { about? What happened then? What are we doing? What aspect is } \\
\text { helpful for you in stopping child abuse in your family?" First, } \\
\text { the case manager has to approve the document. Then, parents, } \\
\text { therapist and case manager share the story with the children and } \\
\text { the social network of the family. In this way, the secrecy } \\
\text { surrounding child abuse and domestic violence is broken. }\end{array}$ \\
\hline $\begin{array}{l}\text { 4. Preliminary guidelines for } \\
\text { family safety }\end{array}$ & $\begin{array}{l}1 \text { session with parents, therapists, case managers } \\
\text { and the social network }\end{array}$ & $\begin{array}{l}\text { Investigating how family life needs to be organised to ensure that } \\
\text { the children are safe in the future. The mutually agreed plans } \\
\text { will prevent further allegations against the alleged perpetrator. }\end{array}$ \\
\hline 5. The family next door & 4 sessions with parents & $\begin{array}{l}\text { In a role-playing game, parents play another family, in which } \\
\text { parents admit abuse, resembling the alleged abuse of the par- } \\
\text { ents. The therapist interviews the parents in their roles as the } \\
\text { other parents. The purpose of this intervention is to increase } \\
\text { knowledge about power dynamics, seduction (grooming), and } \\
\text { the behaviour of the perpetrator. It is not meant to elicit a } \\
\text { confession. }\end{array}$ \\
\hline $\begin{array}{l}\text { 6. The final safety plan for the } \\
\text { family }\end{array}$ & $\begin{array}{l}2 \text { sessions with therapist, parents, case manager, } \\
\text { social network and professional network }\end{array}$ & $\begin{array}{l}\text { Making a final safety plan that describes a future living situation } \\
\text { that enables unity. }\end{array}$ \\
\hline 7. Follow-up & $\begin{array}{l}2 \text { sessions with therapist, parents, case manager, } \\
\text { social network and professional network }\end{array}$ & $\begin{array}{l}\text { Two follow-up booster sessions, } 1 \text { to } 3 \text { months, and } 1 \text { to } \\
6 \text { months to review the implementation of the security plan. }\end{array}$ \\
\hline
\end{tabular}

a Safety card is an element from Signs of Safety protocol

rated by the child and the parent. It measures psychological and physical child abuse and neglect (21 items on an 8-point scale). Reliability indices range from low to moderate, and evidence for construct and discriminant validity of the subscales was found: 'Overall physical assault on the child' $(\alpha=.55)$, 'Psychological Aggression towards the child' $(\mathrm{a}=.60)$, and 'Nonviolent discipline $(\alpha=.70)$ (Straus et al. 1998). For the child, the same items as in the Dutch Prevalence Study of Child Maltreatment (Euser et al. 2013) are used capturing being witness of psychological -, physical -, sexual violence and injuries due to parental fight.

The Revised Conflict Tactics Scale (CTS2; Straus 2014) is a self-report instrument measuring psychological -, physical -, sexual violence and injuries due to a fight with the (ex-)partner, completed by one parent about the other parent (78 items on an 8-point scale). Good construct validity, discriminant validity and internal consistency have been reported with $\alpha=.79$ for assault victimisation and $\alpha=.81$ for assault perpetration. The Dutch version has an acceptable to good reliability, with $\alpha=.82$ for assault victimisation and $\alpha=.65$ for assault perpetration (Straus and Mickey 2012).

\section{Secondary Outcome Measures: Posttraumatic Stress} Symptoms, Emotional and Behavioral Problems in Children, Parental Stress and Closeness of Child-Parent Relationship The Revised Children's Responses to Trauma Inventory (CRTI-R; Alisic and Kleber 2010) is a self-report questionnaire designed to measure child posttraumatic stress symptoms, completed by parents and children (34 items on a 5-point scale). Good reliability of the questionnaire has been reported with a total $\alpha=.91$ (Alisic and Kleber 2010; Alisic et al. 2006).

Strengths and Difficulties Questionnaire (SDQ; Goodman 2001). The SDQ is a self-report questionnaire that assesses social-emotional and behavioral problems in children and adolescents (3-17 years) as reported by parents and children. The questionnaire consists of five subscales: emotional 
Table 2 The assessments specified by the instrument, the construct, the reporters and the time point of the assessment

\begin{tabular}{|c|c|c|c|}
\hline Instrument & Construct & Reporter(s) & Time point \\
\hline Childhood Trauma Questionnaire (CTQ) & $\begin{array}{l}\text { Experiences of maltreatment } \\
\text { and neglect }\end{array}$ & Children & - Extensive measurement $\mathrm{T} 0-\mathrm{T} 4$ \\
\hline $\begin{array}{l}\text { Conflict Tactics Scale Child-Parent } \\
\text { (CTS-CP) }\end{array}$ & Incidents of child abuse & Children and parents & axtensive measurement $\mathrm{T} 0-\mathrm{T} 4$ \\
\hline $\begin{array}{l}\text { Revised Conflict Tactics Scale between } \\
\text { partners (CTS2) }\end{array}$ & Incidents of partner violence & Children and parents & - Extensive measurement T0-T4 \\
\hline $\begin{array}{l}\text { The Nijmeegse Ouderlijke Stress } \\
\text { Index Kinderen (NOSIK) }\end{array}$ & Parental stress & Parents & - Extensive measurement T0-T4 \\
\hline $\begin{array}{l}\text { Children's Responses to Trauma } \\
\text { Inventory (CRTI) }\end{array}$ & $\begin{array}{l}\text { Children's posttraumatic stress } \\
\text { reactions }\end{array}$ & Children and parents & - Extensive measurement $\mathrm{T} 0-\mathrm{T} 4$ \\
\hline $\begin{array}{l}\text { Strengths and Difficulties Questionnaire } \\
\text { (SDQ) }\end{array}$ & $\begin{array}{l}\text { Emotional and behavioural } \\
\text { problems in children }\end{array}$ & Children and parents & - Extensive measurement $\mathrm{T} 0-\mathrm{T} 4$ \\
\hline $\begin{array}{l}\text { The Inclusion of Other in the Self } \\
\text { Scale (IOS) }\end{array}$ & $\begin{array}{l}\text { Closeness of the parent-child } \\
\text { relationship }\end{array}$ & Children & - Extensive measurement $\mathrm{T} 0-\mathrm{T} 4$ \\
\hline Idiosyncratic assessment & $\begin{array}{l}\text { - Items derived from T0 CTS2, } \\
\text { CTS-PC/CP and NOSIK } \\
\text { - Openess of communication } \\
\text { VAS-scale }\end{array}$ & Children and parents & $\circ$ Weekly Idiosyncratic Assessment \\
\hline VAS safety scale & The subjective safety of this family & $\begin{array}{l}\text { Children, parents, social } \\
\text { network members }\end{array}$ & - Each multi-disciplinary meeting \\
\hline Qualitative interview & $\begin{array}{l}\text { Semi-structured interview about } \\
\text { the treatment mechanisms and } \\
\text { most potent techniques }\end{array}$ & $\begin{array}{l}\text { Children, parents and } \\
\text { professionals }\end{array}$ & $\square$ Post-treatment (T2) \\
\hline
\end{tabular}

symptoms, conduct problems, hyperactivity/inattention, peer relationship problems and pro-social behavior (25 items on a 3 -point scale). The total score on the SDQ has satisfactory validity and reliability, with $\alpha=.73$ Goodman (2001). The Dutch SDQ has good validity and acceptable internal consistency, with $\alpha=.70$ for the parent version and $\alpha=.64$ for the self-report version (Goodman et al. 2000).

The Dutch Parental Stress Index-child report (Nijmeegse Ouderlijke Stress Index Kinderen; NOSIK; Brock et al. 1992; Prinzie et al. 2007) is a self-report questionnaire (25 items on a 6-point scale) assessing parental stress as rated by parents themselves. The Parental Stress Index has acceptable reliability, and content, concurrent, and construct validity (Loyd and Abidin 1985; Prinzie et al. 2007). The NOSIK has good reliability, with $\alpha=.95$ (Brock et al. 1992).

The Inclusion of Other in the Self Scale (IOS; Aron et al. 1992) is a single-item, pictorial measure used to assess the closeness of the relationship between children and their parents/caregivers, as assessed by the child (1 item per parent, on a 7-point scale.) The child has to choose one image that best represents their relationship with the parent. The images consist of two circles, which increase in the degree of overlap, the more overlap, the more closeness. Convergent validity, discriminant validity and predictive validity of IOS were acceptable. The reliability was investigated using different formats of the response scale (circle and diamond); Chronbach's alpha was .93 , and test-retest reliability was $r=.83$ (Aron et al. 1992).
Idiosyncratic Assessments In addition to the extensive measurements at five assessment points, the parents and children complete a short Idiosyncratic Assessment (IA) on a weekly base during the baseline and treatment phases (T0-T2). The IA is a personalised questionnaire including 5 to 10 items representing top family problems as indicated during the intake and first assessment point (T0). Such a short questionnaire allows monitoring of the main family complaints on a regular base but also meets the needs of families and clients characterized by heterogeneity (Weisz et al. 2011). The IA items are derived from three questionnaires filled in during the T0: two primary outcome measures, measuring incidents of child abuse and domestic violence (CTS2, CTS-CP/PC), and one secondary outcome measure (NOSIK) measuring parental stress. The idea is to select the items on which the client reports the most problems, but, prior to the selection, client and therapist are also asked separately to identify the most distressing problems (types of child abuse) for him/her and the family environment. During this selection, the opinion of the participant and the therapist is also taken into account. The reason for this is to specify the most distressing problems for the participant and his/her environment. They can choose between types of abuse and domestic violence, which are derived from the subscales of CTS2 and CTS: (a) Parent-child: sexual-, emotional-, physical abuse, or injury; (b) Partner-partner: emotional- or physical abuse. It is possible to get biased results if the selection was based only on the least adaptively rated items on the questionnaire. This is mainly because the CTS2 and CTS-CP/PC measure the abuse on a frequency- 
scale. However, it is possible that a participant is more frequently abused emotionally, but that she/he finds the physical abuse worse. For the parental stress items, 1-3 items are always chosen related to the least adaptively rated items on the NOSIK.

Multidisciplinary Social Network Meetings Ratings These meetings are planned approximately every six weeks during the intervention period (T1-T2). Parents, children and social-, and professional network members score the subjective safety of this family at the end of the multidisciplinary network meetings on a VAS- scale ranging from " $0=$ Recurrence of similar or worse abuse/neglect is certain" to " $10=$ Sufficient safety for the child for the case to be closed" (Turnell and Edwards 1999).

\section{Mechanisms of Change}

Specific attention will be given to the ratings of parental stress and openness of communication as clinical experience suggests that these constructs may be important mechanisms of change behind RA effects. Idiosyncratic assessments of parental stress as outlined above will be used to achieve this aim. Further, via a newly constructed VAS-scale, openness of communication about child abuse and safety will be assessed weekly via the following items: "In our family (parents + children) we talk about the concerns related to the safety of our children" and "We (our family = parents + children) talk with our extended family and friends about the concerns related to the safety of our children." on a scale ranging from " $0=$ we never talk..." to " $100=$ we talk frequently with..."

Next to this, potential mechanisms will be assessed in the qualitative, semi-structured interview administered to the children and the parents at the end of the treatment. Qualitative data gathered at post-treatment (e.g., asking the client: "What aspect was the most helpful for you in stopping child abuse in your family?") could provide unique insights into the process of the treatment (Dworkin et al. 2006). The goal of the interview is to acquire a better understanding of these potential mechanisms, and to discover other possible mechanisms involved in the remediation of child abuse for each family.

The qualitative approach allows us also to investigate the most effective RA components for each family, and also to examine the satisfaction with the treatment and the collaboration between professionals and the family. Interview utilized in Gumbleton's study (1997) is serving as a starting point for the construction of our own interview. Main topics from our interview will include: (a) Has the safety of the children been improved and has the openness of communication about child abuse increased? (b) Did the family members reach their goals? (c) Which treatment elements helped in achieving the goals?

\section{Treatment Integrity}

All of the therapists are trained and experienced in RA. To ensure treatment integrity, therapists mark the employed RA elements on a checklist after each session. If additional trauma treatment is conducted, this will be noted. Finally, all of the therapists will participate in regular supervision sessions provided by the first author.

\section{Data-Analytic Approach}

To test the effectiveness of RA on primary and secondary outcome measures the following analyses will be conducted. First, Reliable Change Index (RCI; Jacobson and Truax 1991) will be calculated for each participant. The RCI facilitates the investigation of clinically meaningful change (i.e., as compared to a norm group) in the outcomes from pre- to posttreatment, and pre- to follow/up treatment. An RCI $>1.96$ or $<-1.96$ (z-scores) indicates a statistically significant reliable change (Jacobson and Truax 1991). Second, a mixedmodels method in SPSS (Maric et al. 2015) will be used to assess statistically-relevant within-person change in outcomes between the end of the baseline phase and the end of the treatment phase. This new-generation SCED data-analytic method requires less data observation points per phase (i.e., 4-5) to calculate betweenphase differences than the more traditional SCED methods (Barlow et al. 2009).

Cross-lagged correlations will be used for the analyses of the mechanisms of change. Temporal relations and direction of changes in frequency and type of incidents of child abuse, level of parental stress and openness of communication about child abuse will be investigated. The qualitative data from the interviews will be analysed by the Thematic Analysis of Qualitative Data (Braun and Clarke 2006) using the software Atlas.ti (ATLAS.ti 2016).

\section{Handling and Storage of Data and Documents}

A personalised code is assigned to each participant in this study for the anonymous data storage. This code represents the participating mental health centre, family and the role of the participant (e.g., father, mother, oldest child). The participant fills in his/her personalised code at every extensive assessment point and this is conducted by the software Qualtrics. The idiosyncratic assessments are personalised and linked to the same code. The informed consent contains the name, email address, phone number and personalised code of the participant. The involved mental health care centers store the informed consent in protected files for administrative purposes. The copies of informed consent forms are securely stored at the University of Amsterdam (UvA), and only the second and the last author have access to them. 


\section{Sample Size}

A method to enhance the generalisability of the SCED's is the use of replication (Graham et al. 2012). Multiple SCED's will be conducted. The aim is to achieve a scientific consensus about the effectiveness of the intervention considering the difference in participants, clinicians and settings. According to the guidelines of the Task Force of the American Psychological Association (1995) an intervention can be considered as well-established if a series of at least nine single case design studies demonstrate efficacy. We will aim at including at least 15 families taking into account possible dropouts.

\section{Discussion}

Despite the high prevalence rates and the severe consequences of child abuse, we know little about effective approaches to stop child abuse and enhance safety. In the Netherlands, as well as abroad (e.g., United Kingdom, Australia, Japan), professionals in youth care institutions use one of the two solution-focused approaches to stop child abuse: SofS (Turnell and Edwards 1999) and RA (Turnell and Essex 2006). The aim of RA is to stop child abuse and enhance safety for the child in families where parents (partly) deny the child abuse. Despite its frequent use in the clinical practice, scarce studies on its effectiveness have been conducted. The current research study described in this protocol article, aims to investigate the effectiveness of the RA in Dutch families with a history of child abuse, and to investigate potential mechanisms of change. To our knowledge, within the Netherlands and abroad, this is aimed to be the first reported study investigating the effectiveness of the RA using quantitative methods.

Because of the high heterogeneity of problems identified in these families, the innovative character of this treatment, and earlier unsuccessful attempts to conduct RCT's in this population, the SCED methodology is implemented in this study. Before, during and after intervention we will assess type and frequency of incidents of child abuse and domestic violence, posttraumatic stress symptoms, social-emotional/ behavioral functioning of the child, parental stress, closeness of the parent-child relationship, and openness of the communication about abuse. Both qualitative and quantitative assessment tools are used, and data are collected from children, parents, and professionals. Innovative statistical techniques are used to inspect the data.

In the first place the research study can provide us with empirical information about how potent this intervention is in decreasing and stopping the incidents of child abuse and domestic violence as well as in decreasing parental stress. Further, the study can inform us whether the participating children have emotional and behavioural problems and whether those symptoms diminish while safety augments. Based on clinical experience, we do expect to observe changes in the closeness of the child-parent relationship during treatment. In the second place, we expect to gain knowledge about the potential mechanisms of change behind intervention effects. For example, the increased openness of communication may be related to fewer incidents of child abuse. Secondary gains of this study will be that the conduct of this research will provide us with rich experience in testing and researching these families and in motivating them to participate in the research

We are aware of several anticipated challenges of the research study. First, the possibility of high rates of treatment drop-outs or research study drop-outs. A special researcher (the second author) is appointed to monitor the collection of the data closely to avoid drop-outs. The role of this researcher is to achieve a close relationship with families regarding assessments, to motivate the clients for the assessments, to provide answers to emerging questions (by phone and email) regarding assessments, to phone parents when assessments are missing, or if parents have reading problems, and to assist the parents with completion of assessments.

A second anticipated challenge of the research study is the potential bias in parental reports of child abuse. We deal with this challenge by using multiple informants (parents, children, professionals) and multiple measures: primary measures by which we measure incidents of child abuse, secondary measures by which we measure parental stress, children's posttraumatic stress reactions, emotional and behavioral problems in children, and the parent-child relationship. Furthermore, clients are well aware that only the researchers see the primary measures' scores and that the data are stored anonymously. The children are informed that the parents do not see their answers to the questionnaire items. Straus et al. (1998) who developed and investigated the primary measures used in our study, the CTS2 and CTS-CP/PC scales, commented on the challenge of measuring child abuse by parents who deny the abuse. He observed that the overall yearly incidence rate for severe assaults as measured by the CTS-PC scales is several times larger than the rate of officially registered cases, suggesting that parents are perhaps not underreporting on questionnaires. Nevertheless, it is probably best to consider the information provided by the CTSPC as a minimum estimate of child abuse (Straus et al. 1998).

A third challenge concerns an ongoing discussion as to whether children are reliable reporters of child abuse. Scarce studies on related topics using qualitative methods (Finan et al. 2016) indicate that it is not only possible to elicit useful feedback from children about child abuse treatment, but also that child reports on their own maltreatment are valid and predictive of their own emotional symptoms. This is even more so for children in the age between 9 and 18 years 
(Sierau et al. 2017). Our goal in the present study is to involve children and parents in the assessment process. The fact that analyses are conducted on a single-case level using quantitative and qualitative methods enables us to evaluate reported information critically and to have client input and feedback.

To conclude, RA is already implemented in clinical practice and is eliciting positive results and experiences based on both therapist and client reports. The research study described in this article is aimed at providing an initial evidence-base for this clinical program.

Author's Contribution All authors contributed to the design of the study. AS and MM obtained funding for the study. AS and VvdW coordinated the recruitment of participants. VvdW coordinates the data collection. MM and TM supervise the progress of the study. All authors contributed to the writing of the manuscript. All authors read and approved the final manuscript.

Funding This study is funded by The Netherlands Organisation for Health Research and Development (ZonMW; Grant number 707410098002; contact: https://www.zonmw.nl/nl/onderzoek-resultaten/ jeugd/programmas/programma-detail/kindermishandeling/projecten/).

Data Availability Data collection is ongoing (start date: May 1st, 2017). We have developed a Data Management Plan (DMP) in collaboration with data management experts at the University of Amsterdam (UvA). The UvA acknowledges the interest of sharing datasets after the primary authors have published all their manuscripts based on these data. In this case, because we are gathering data involving vulnerable families, some restrictions regarding data-sharing will be built into the DMP.

\section{Compliance with Ethical Standards}

Competing Interests The authors declare that they have no competing interests.

Ethics Approval and Consent to Participate The Ethics Review Board of the University of Amsterdam, Department of Psychology, has approved the study protocol on 2017-3-27 under number 2017-DP-7892. Parents or primary caregivers sign the informed consent for their own and their child's or adolescent's participation. Adolescents (12+) are also requested to sign their informed consent.

Open Access This article is distributed under the terms of the Creative Commons Attribution 4.0 International License (http:// creativecommons.org/licenses/by/4.0/), which permits unrestricted use, distribution, and reproduction in any medium, provided you give appropriate credit to the original author(s) and the source, provide a link to the Creative Commons license, and indicate if changes were made.

\section{References}

Alisic, E., \& Kleber, R. J. (2010). Measuring posttraumatic stress reactions in children: A preliminary validation of the children's responses to trauma inventory. Journal of Child and Adolescent Trauma, 3, 192-204. https://doi.org/10.1080/19361521.2010. 500979 .
Alisic, E., Eland, J., \& Kleber, R. J. (2006). Children's responses to trauma inventory - revised version. Utrecht: Institute for Psychotrauma in collaboration with clinical psychology Utrecht University and Psychotrauma Center for Children and Youth (UMC Utrecht).

Aron, A., Aron, E. N., \& Smollan, D. (1992). Inclusion of other in the self scale and the structure of interpersonal closeness. Journal of Personality and Social Psychology, 63, 596-612. https://doi.org/10.1037/0022-3514.63.4.596.

ATLAS.ti. Version 8.0. (2016) Berlin: Scientific software development $\mathrm{GmbH}$, Berlin.

Barlow, D. H., Nock, M. K., \& Hersen, M. (2009). Single case experimental designs. Strategies for studying behavior change (3rd ed.). Boston: Allyn and Bacon.

Bernstein, D. P., Ahluvalia, T., Pogge, D., \& Handelsman, L. (1997). Validity of the childhood trauma questionnaire in an adolescent psychiatric population. Journal of American Academy Child and Adolescent Psychiatry, 36, 340-348. https://doi.org/10.1097/ 00004583-199703000-00012.

Bernstein, D. P., Stein, J. A., Newcomb, M. D., Walker, E., Pogge, D., Ahluvalia, T., \& Zule, W. (2003). Development and validation of a brief screening version of the childhood trauma questionnaire. Child Abuse and Neglect, 27, 169-190. https://doi.org/10.1016/S01452134(02)00541-0.

Borckardt, J. J., Nash, M. R., Murphy, M. D., Moore, M., Shaw, D., \& O'Neil, P. (2008). Clinical practice as natural laboratory for psychotherapy research. American Psychologist, 63, 77-95. https://doi.org/ 10.1037/0003-066X.63.2.77.

Braun, V., \& Clarke, V. (2006). Using thematic analysis in psychology. Qualitative Reserach in Psychology, 3, 77-101. https://doi.org/10. 1191/1478088706qp063oa.

Brock, A. J. L. L., Vermulst, A. A., Gerris, J. R. M., \& Abidin, R. R. (1992). NOSI, Handleiding Nijmeegse Ouderlijke Stress Index. Amsterdam: Pearson.

Dworkin, S. L., Exner, T., Melendez, R., Hoffman, S., \& Ehrhardt, A. A. (2006). Revisiting success: Posttrial analysis of a gender-specific HIV/STD prevention intervention. AIDS and Behavior, 10, 41-51. https://doi.org/10.1007/s10461-005-9023-0.

Euser, S., Alink, L. R., Pannebakker, F., Vogels, T., BakkermansKranenburg, M. J., \& van IJzendoorn, M. H. (2013). The prevalence of child maltreatment in the Netherlands across a 5-year period. Child Abuse and Neglect, 37, 841-851. https://doi.org/10.1016/j. chiabu.2013.07.004.

Felitti, V. J., Anda, R. F., Nordenberg, D., Williamson, D. F., Spitz, A. M., Edwards, V., \& Marks, J. S. (1998). Relationship of childhood abuse and household dysfunction to many of the leading causes of death in adults: The adverse childhood experiences study. American Journal of Preventive Medicine, 14, 245-258. https://doi.org/10.1016/ s0749-3797(98)00017-8.

Finan, S., Salveron, M., \& Bromfield, L. (2016). "Listen to me": Exploring children's participation during child protection assessment. Communities, Children and Families Australia, 10, 27-44.

Goodman, R. (2001). Psychometric properties of the strengths and difficulties questionnaire. Journal of American Academy Child and Adolescent Psychiatry, 40, 1337-1345. https://doi.org/10.1097/ 00004583-200111000-00015.

Goodman, R., Ford, T., Simmons, H., Gatward, R., \& Meltzer, H. (2000). Using the strengths and difficulties questionnaire (SDQ) to screen for child psychiatric disorders in a community sample. The British Journal of Psychiatry, 177, 534-539. https://doi.org/10.1192/bjp.6.534.

Government of Western Australia, Department for Child Protection. (2011). The signs of safety, child protection practice framework. Retrieved from https://www.dcp.wa.gov.au/Resources/Documents/Policies\% 20and\%20Frameworks/SignsOfSafetyFramework2011.pdf. Access 15 April 2019 
Graham, J. E., Karmarkar, A. M., \& Ottenbacher, K. J. (2012). Small sample research designs for evidence-based rehabilitation: Issues and methods. Archives of Physical Medicine and Rehabilitation, 93, S111-S116. https://doi.org/10.1016/j.apmr.2011.12.017.

Gumbleton, J. (1997). Untreatable families?: Working with denial in cases of severe child abuse. Bristol: University of Bristol.

Hammink, A., Cobussen, M., van Ruiten-Verkuijl, S., van Arum, S., Visser, M., de Graaf, I., \& van de Mheen, D. (2015). Veiligheid van kinderen boven alles: Intersectoraal samenwerken met veilig, sterk en verder. Kind en Adolescent Praktijk, 14, 28-34. https://doi. org/10.1007/s12454-015-0031-6.

Jacobson, N. S., \& Truax, P. (1991). Clinical significance: A statistical approach to defining meaningful change in psychotherapy research. Journal of Consulting and Clinical Psychology, 59, 12-19. https:// doi.org/10.1037/0022-006X.59.1.12.

Loyd, B. H., \& Abidin, R. R. (1985). Revision of the parenting stress index. Journal of Pediatric Psychology, 10, 169-177. https://doi. org/10.1093/jpepsy/10.2.169.

Mabanglo, M. A. G. (2002). Trauma and the effects of violence exposure and abuse on children: A review of the literature. Smith College Studies in Social Work, 72, 231-251. https://doi.org/10.1080/ 00377310209517657.

Maguire, S. A., Williams, B., Naughton, A. M., Cowley, L. E., Tempest, V., Mann, M. K., \& Kemp, A. M. (2014). A systematic review of the emotional, behavioral and cognitive features exhibited by schoolaged children experiencing neglect or emotional abuse. Child: Care, Health and Development, 41, 641-653. https://doi.org/10.1111/cch. 12227.

Maric, M., Wiers, R. W., \& Prins, P. J. M. (2012). Ten ways to improve the use of statistical mediation analysis in the practice of child and adolescent treatment research. Clinical Child and Family Psychology Review, 15, 177-191. https://doi.org/10.1007/s10567012-0114-y.

Maric, M., de Haan, E., Hogendoorn, S. M., Wolters, L. H., \& Huizenga, H. M. (2015). Evaluating statistical and clinical significance of intervention effects in single-case experimental designs: An SPSS method to analyze univariate data. Behavior Therapy, 46, 230-241.

Norell-Clarke, A., Nyander, E., \& Jansson-Fröjmark, M. (2011). Sleepless in Sweden: A single subject study of effects of cognitive therapy for insomnia on three adolescents. Behavioral and Cognitive Psychotherapy, 39, 367-374. https://doi.org/10.1017/ S1352465810000664.

Prinzie, P., Onghena, P., \& Hellinckx, W. (2007). Reexamining the parenting scale: Reliability, factor structure, and concurrent validity of a scale for assessing the discipline practices of mothers and fathers of elementary-school-aged children. European Journal of Psychological Assessment, 23, 24-31. https://doi.org/10.1027/ 1015-5759.23.1.24

Salveron, M., Bromfield, L., Kirika, C., Simmons, J., Murphy, T., \& Turnell, A. (2015). Changing the way we do child protection: The implementation of the signs of safety within the Western Australia Department of Child Protection and Family Support. Children and Youth Services Review, 48, 126-139.

Sedlak, A. J., Mettenburg, J., Basena, M., Petta, I., McPherson, K., Greene, A., \& Li, S. (2010). Fourth national incidence study of child abuse and neglect (NIS-4): Report to Congress. U.S. Department of Health and Human Services, Administration for Children and Families.

Sierau, S., Brand, T., Manly, J. T., Schlesier-Michel, A., Klein, A. M., Andreas, A., Garzón, L. Q., Keil, J., Binser, M. J., von Klitzing, K., \& White, L. O. (2017). A multisource approach to assessing child maltreatment from records, caregivers, and children. Child Maltreatment, 22, 45-57.

Skrypek, M,. Idzelis, M,. \& Pecora, P.J. (2012). Signs of safety in Minnesota: Parent perceptions of a signs of safety child protection experience. Minnesota: Wilder research. Retrieved from http://bayareaacademy.org/wpcontent/uploads/CaseyFoundation-Birth-Parent-Perceptions.

Stoltenborgh, M., Bakermans-Kranenburg, M. J., Alink, L. R. A., \& van IJzendoorn, M. H. (2015). The prevalence of child abuse across the globe: Review of a series of meta-analyses. Child Abuse Reviews, 24, 37-50. https://doi.org/10.1002/car.2352.

Straus, M. A. (2014). Cross-cultural reliability and validity of the revised conflict tactics scales: A study of university student dating couples in 17 nations. Cross-Cultural Research, 38, 407-432. https://doi.org/10.1177/1069397104269543.

Straus, M. A., \& Mickey, E. L. (2012). Reliability, validity, and prevalence of partner violence measured by the conflict tactics scales in male-dominant nations. Aggression and Violent Behavior, 17, 463 474. https://doi.org/10.1016/j.avb.2012.06.004

Straus, M. A., Hamby, S. L., Finkelhor, D., Moore, D. W., \& Runyan, D. (1998). Identification of child maltreatment with the parent-child conflict tactics scales: Developmental psychometric data for a national sample of American parents. Child Abuse and Neglect, 22, 249-270. https://doi.org/10.1016/S0145-2134(97)00174-9.

Task Force on Promotion and Dissemination of Psychological Procedures, Division of Clinical Psychology, American Psychological Association. (1995). Training in and dissemination of empirically validated psychological treatments: Report and recommendations. The Clinical Psychologist, 48, 3-23.

Thombs, B. D., Bernstein, D. P., Lobbestael, J., \& Arntz, A. A. (2009). Validation study of the Dutch childhood trauma questionnaire-short form: Factor structure, reliability, and known-groups validity. Child Abuse and Neglect, 33, 518-523. https://doi.org/10.1016/j.chiabu. 2009.03.001.

Turnell, A., \& Edwards, S. (1999). Sings of safety: A solutions and safety oriented approach to child protection casework. New York: Norton \& Company.

Turnell, A., \& Essex, S. (2006). Working with 'denied' child abuse: The resolutions approach. Maidenhead: Open University Press.

Vink, R., Wolff, M. de., Dommelen, P. van, Bartelink, C., \& Veen, S. (2017) Empowered door Signs of Safety? Onderzoek naar de werkzaamheid van Signs of Safety in de jeugdzorg. TNO. https:// www.nji.nl/nl/Download-NJi/Publicatie-NJi/Empowered-doorSigns-of-Safety-Onderzoek.pdf. Access 15 April 2019

Vogtländer, L., \& van Arum, S. (2016). Eerst samenwerken voor veiligheid, dan samenwerken voor risicogestuurde zorg Een duurzame visie op ketenzorg bij kindermishandeling, huiselijk geweld en seksueel misbruik en de centrale rol hierbij van het triage-instrument Veilig Thuis. GGD GHOR Nederland. https://vng.nl/files/vng/201605_visiedocument_gefaseerde ketensamenwerkingvogtlander_van_arum_0.pdf

Weisz, J. R., Chorpita, B. F., Frye, A., Ng, M. Y., \& Hoagwood, K. E. (2011). Youth top problems: Using idiographic, consumer-guided assessment to identify treatment needs and to track change during psychotherapy. Journal of Consulting and Clinical Psychology, 79, 369-380.

Publisher's Note Springer Nature remains neutral with regard to jurisdictional claims in published maps and institutional affiliations. 